\title{
Use of the Wasserman equation in optimization of the duration of the power ramp in a cardiopulmonary exercise test: a study of Brazilian men
}

\author{
D.C. Costa, G.L. De Santi, J.C. Crescêncio, L.P. Seabra, E.E.V. Carvalho, V. Papa, F. Marques, \\ L. Gallo Junior and A. Schmidt \\ Laboratório de Fisiologia do Exercício, Divisão de Cardiologia, Departamento de Clínica Médica, Hospital das Clínicas, \\ Faculdade de Medicina de Ribeirão Preto, Universidade de São Paulo, Ribeirão Preto, SP, Brasil
}

\begin{abstract}
This study aimed to analyze the agreement between measurements of unloaded oxygen uptake and peak oxygen uptake based on equations proposed by Wasserman and on real measurements directly obtained with the ergospirometry system. We performed an incremental cardiopulmonary exercise test (CPET), which was applied to two groups of sedentary male subjects: one apparently healthy group $(H G, n=12)$ and the other had stable coronary artery disease $(n=16)$. The mean age in the HG was $47 \pm 4$ years and that in the coronary artery disease group (CG) was $57 \pm 8$ years. Both groups performed CPET on a cycle ergometer with a ramp-type protocol at an intensity that was calculated according to the Wasserman equation. In the HG, there was no significant difference between measurements predicted by the formula and real measurements obtained in CPET in the unloaded condition. However, at peak effort, a significant difference was observed between oxygen

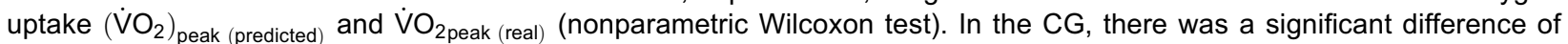
$116.26 \mathrm{~mL} / \mathrm{min}$ between the predicted values by the formula and the real values obtained in the unloaded condition.

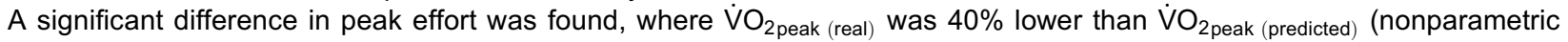
Wilcoxon test). There was no agreement between the real and predicted measurements as analyzed by Lin's coefficient or the Bland and Altman model. The Wasserman formula does not appear to be appropriate for prediction of functional capacity of volunteers. Therefore, this formula cannot precisely predict the increase in power in incremental CPET on a cycle ergometer.
\end{abstract}

Key words: Wasserman equation; Cardiopulmonary exercise test; Coronary artery disease; Cardiovascular diagnostic techniques

\section{Introduction}

The cardiopulmonary exercise test (CPET) has greatly changed the approach to functional evaluation by relating physical fitness and physiological parameters to the underlying metabolic substrate and by providing highly reproducible descriptors of effort capacity. The CPET provides an accurate and objective measurement of functional capacity and of the integrity of the cardiovascular and respiratory systems. Therefore, the CPET has been indicated for assessment of functional capacity in high-performance athletes, for diagnostic purposes, and for evaluation of pharmacological or nonpharmacological therapies, preoperative risk, and for risk stratification. Variables, such as oxygen uptake $\left(\dot{V}_{2}\right)$ represent an objective measure of functional capacity and reflect the severity of diseases, such as myocardial ischemia, heart failure, hypertrophic cardiomyopathy, and pulmonary artery hypertension secondary to interstitial or chronic obstructive pulmonary disease $(1,2)$.

The CPET is considered to be the most accurate method for assessment of aerobic power. However, different values may be obtained for the same individual when different modalities of the test are used $(3,4)$. From a methodological point of view, two aspects crucially interfere with the quality of the test and the reproducibility of the response of the variables: the type of protocol and the duration of the effort tests.

Ramp protocols have become popular because they permit individualized tests. This is possible because load increment occurs constantly and continuously at a rate that can be individualized according to the capacity of the individual (5-8).

Correspondence: D.C. Costa: <danielacosta@usp.br>.

Received January 19, 2015. Accepted May 21, 2015. First published online September 18, 2015. 
The Wasserman equation (9) has been routinely used for many years in the Laboratório de Fisiologia do Exercício, Faculdade de Medicina de Ribeirão Preto. This equation is used for the choice of progressive load increment on a cycle ergometer during the CPET, and is applied to healthy individuals and to those with ischemic myocardial disease. This practice is based on the search for a less empirical and subjective manner of choosing the intensity of the power ramp to be applied to incremental effort tests on a cycle ergometer.

Elaboration of a formula for the calculation of load increment in a ramp-type incremental CPET by Wasserman et al. (9) proved to be helpful for choosing the most appropriate intensity for optimization of the quality of the CPET. However, in many cases, a simple estimate of the power increment according to this formula can underestimate or overestimate the real functional capacity of a healthy individual or a patient. Marked characteristics of health status, as well as disease status, directly interfere with the performance and homeostasis of the cardiopulmonary and musculoskeletal systems during exercise.

The present study aimed to analyze the agreement between measurements of unloaded oxygen uptake $\left(\dot{\mathrm{V}} \mathrm{O}_{2 \text { unloaded (predicted) }}\right)$ and peak oxygen uptake $\left(\dot{\mathrm{VO}}_{2 \text { peak (predicted) }}\right)$ predicted from the equations proposed by Wasserman and real measurements $\left(\dot{\mathrm{V}}_{2 \text { unloaded (real) }}\right.$, $\dot{\mathrm{VO}}_{2 \text { peak (real) }}$ ), which were directly obtained in an incremental ramp-type CPET. We studied a sample of apparently healthy sedentary males and a sample of sedentary males with coronary artery disease (CAD).

\section{Material and Methods}

Two groups of sedentary males were selected. The healthy group (HG) consisted of 12 apparently healthy sedentary volunteers, aged $47 \pm 4$ years, who were recruited through the media. For inclusion in the study, all of the subjects were submitted to clinical evaluation and to a resting electrocardiogram to exclude asymptomatic heart disease or a history of cardiac or pulmonary disease or any orthopedic limitation. Current smokers and/or alcoholics, and subjects taking antihypertensive drugs or beta-blockers, or any other medication that would alter the response of the subject to physical effort were excluded.

The other group was the coronary artery disease group (CG). This group consisted of 16 sedentary individuals, aged $57 \pm 8$ years, who were recruited at the outpatient clinic of the institution. The subjects met at least one of the following inclusion criteria: a history of acute myocardial infarction that was clinically confirmed and/or by complementary exams, previous coronary angiography with documentation of coronary injury with more than $70 \%$ obstruction of the luminal diameter, and a previous noninvasive exam (stress echocardiogram or myocardial perfusion scintigraphy) with documentation of effort ischemia. All of the patients had been clinically stable for at least the last 3 months, with optimized pharmacological treatment and no indication of new revascularization procedures.

The study was approved by the Research Ethics Committee of the Hospital das Clínicas, Faculdade de Medicina de Ribeirão Preto, Universidade de São Paulo, (protocol \#1593/2009). All of the subjects gave written informed consent to participate.

\section{CPET}

The formula proposed by Wasserman (9) was calculated for each individual for performance of the CPET as follows:

$\dot{\mathrm{V}} \mathrm{O}_{2 \text { unloaded }}(\mathrm{mL} / \mathrm{min})=150+(6 \times$ weight, $\mathrm{kg})$

$\dot{\mathrm{V}} \mathrm{O}_{2 \text { peak }}(\mathrm{mL} / \mathrm{min})=($ height : $\mathrm{cm}$, age : years $) \times 20$

$\operatorname{Ramp}(\mathrm{w} / \mathrm{min})=\dot{\mathrm{V}} \mathrm{O}_{2 \text { peak }}-\dot{\mathrm{V}} \mathrm{O}_{2 \text { unloaded }} / 100$

For subjects in the $\mathrm{HG}$, only a decimal approximation of the final result of the formula, in watts/minute, was added by rounding the value to the nearest decimal point. For subjects in the CG, this correction was made based on clinical evaluation and disease conditions, with an average 4.84 watts reduction of the final result. These corrections needed to be applied so that each individual achieved maximum effort, satisfying one or more of the criteria that define $\dot{\mathrm{V}} \mathrm{O}_{2 \text { max }}$, such as a respiratory exchange ratio $(R E R)>1.15$, heart rate at peak effort above $85 \%$ of maximum, and a plateau of oxygen uptake, which was defined as a variation in increase between 1.0 and $2.0 \mathrm{~mL} / \mathrm{kg} / \mathrm{min}$ within 8 to $12 \mathrm{~min}(3,7,10)$.

All of the subjects were submitted to a maximal CPET using a ramp-type incremental protocol. The individuals performed dynamic physical effort in the sitting position on an electromagnetically braked cycle ergometer (Corival 400, Lode BV, The Netherlands). The subjects were encouraged to perform applied effort up to the power at which they reached cardiorespiratory exhaustion and/or the presence of classical interruption criteria as follows: elevation of diastolic blood pressure to $120 \mathrm{mmHg}$ in normotensive subjects and up to $140 \mathrm{mmHg}$ in hypertensive subjects; marked systolic blood pressure elevation up to $260 \mathrm{mmHg}$; and exacerbated chest discomfort with increased load or associated with electrocardiographic changes, such as ischemia, ataxia, dizziness, pallor, cyanosis and presyncope, disproportional dyspnea, complex ventricular arrhythmia, and others $(1,8)$. For all of the subjects, the beginning of the ramp exercise was preceded by 4 min of unloaded effort (3-4 watts) at a constant speed of 60 rotations per minute $(\mathrm{rpm})$. In this protocol, the ventilatory variables were determined using the CPX/D metabolic analysis system (Medical Graphics, USA), which permits the acquisition, processing, and storage of breath-to-breath data. Laboratory conditions were set at $45 \%$ to $60 \%$ air relative humidity and an ambient temperature of approximately $22^{\circ} \mathrm{C}$. 


\section{Calculation of variables obtained with CPET}

After stabilization of pedaling velocity at approximately $60 \mathrm{rpm}$, a segment of approximately $2 \mathrm{~min}$ was selected

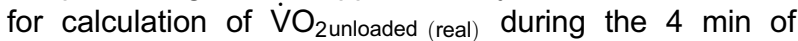
the unloaded period. The last 10 values plotted by the metabolic system were selected for peak effort and the mean $\dot{\mathrm{V}}_{2 \text { peak (real) }}$ was calculated.

\section{Statistical analysis}

Data are reported as mean $\pm S D$ and are presented graphically in box plots. The nonparametric Wilcoxon test was used to compare intragroup means of $\dot{\mathrm{V}} \mathrm{O}_{2 \text { unloaded (predicted) }}, \dot{\mathrm{V}} \mathrm{O}_{2 \text { unloaded (real) }}, \dot{\mathrm{V}} \mathrm{O}_{2 \text { peak (predicted), and }}$ $\dot{\mathrm{VO}}_{2 \text { peak (real). The nonparametric Mann-Whitney test was }}$ used to compare intergroup means for duration of effort,

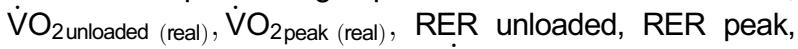
power (peak), and ventilation $(\dot{V})$ peak. The agreement between means was determined using the Lin and Bland and Altman models, with calculation of the mean difference between methods (bias) and the 95\% confidence intervals (Cls) for the limits of agreement.

Lin's concordance coefficient was used to determine whether the measurements that were predicted by the formula and the real measurements that were obtained in the CPET significantly deviated from the perfect concordance line (a $45^{\circ}$ line with origin at 0 of the $x$ and $y$ axes). Excellent concordance was defined as Lin $>0.90$, satisfactory concordance as Lin $0.6-0.9$, and unsatisfactory concordance as Lin $<0.6$. The level of significance was set at $5 \%$.

\section{Results}

The anthropometric characteristics and risks factors of both groups are shown in Table 1. Previous events and interventions, distribution of the left ventricular ejection fraction, and medications used are shown in Table 2.

The duration of effort was $620 \pm 140 \mathrm{~s}$ in the CG, corresponding to $10 \pm 2 \mathrm{~min}$, and $552 \pm 75 \mathrm{~s}$ in the $\mathrm{HG}$, corresponding to $9 \pm 1 \mathrm{~min}$, with no significant difference between the groups $(P=0.09)$.

With regard to the functional capacity of the two groups, during the unloaded period, $\dot{\mathrm{V}} \mathrm{O}_{2 \text { unloaded (real) was }}$ significantly lower in the CG compared with the $\mathrm{HG}$ (524 \pm 67 vs $581 \pm 68 \mathrm{~mL} / \mathrm{min} ; \mathrm{P}=0.02)$. At peak effort, $\dot{\mathrm{VO}}_{2 \text { peak (real) }}$ was significantly lower in the CG compared with the HG $(1327 \pm 287$ vs $2110 \pm 336 \mathrm{~mL} / \mathrm{min}$; $\mathrm{P}<0.0001)$. A similar finding was observed when $\dot{\mathrm{V}} \mathrm{O}_{2 \text { peak (real) }}$ was corrected for weight $\left(\mathrm{mL} \cdot \mathrm{kg}^{-1} \cdot \mathrm{min}^{-1}\right)$, with a lower value in the CG compared with the HG (16 \pm 3 vs $26 \pm 6$; $\mathrm{P}<0.0001$; Figure 1 and Table 3 ).

When the measurements that were predicted by the formula and the real measurements that were obtained in the CPET were compared in the HG, the difference of $39 \mathrm{~mL} / \mathrm{min}$ detected in the unloaded condition between

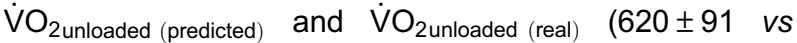
$581 \pm 68 \mathrm{~mL} / \mathrm{min}$ [6\% difference]) was not significant $(P=0.10)$. However, at peak effort, a significant difference was observed between $\dot{\mathrm{VO}}_{2 \text { peak (predicted) }}$ and $\dot{\mathrm{V}} \mathrm{O}_{2 \text { peak (real) }}$ values $(2467 \pm 174$ vs $2110 \pm 336 \mathrm{~mL} / \mathrm{min}[14 \%$ difference]; $P=0.02$; Figure 2A).

In the CG, there was a significant difference between the values that were predicted by the Wasserman (9) formula and the real values that were obtained in the unloaded condition in the CPET $(116 \mathrm{~mL} / \mathrm{min}, \mathrm{P}<0.0001)$, where $\dot{\mathrm{V}}_{2 \text { unloaded (predicted) was }} 640 \pm 80 \mathrm{~mL} / \mathrm{min}$ and $\dot{\mathrm{V}} \mathrm{O}_{2 \text { unloaded (real) }}$ was $524 \pm 67 \mathrm{~mL} / \mathrm{min}$ (18\% difference). A significant difference was also detected at peak effort, where

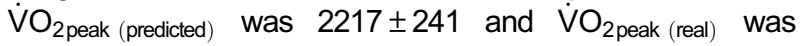
$1327 \pm 287 \mathrm{~mL} / \mathrm{min}(\mathrm{P}<0.0001 ; 40 \%$ difference; Figure $2 \mathrm{~B})$.

Table 1. Anthropometric characteristics and prevalence of risk factors in the healthy and coronary artery disease groups.

\begin{tabular}{lcc}
\hline & Healthy group $(\mathrm{n}=12)$ & Coronary artery disease group $(\mathrm{n}=16)$ \\
\hline Age (years) & $47 \pm 4$ & $57 \pm 8^{*}$ \\
Body mass $(\mathrm{kg})$ & $82.1 \pm 15.9$ & $81.7 \pm 13.4$ \\
Height $(\mathrm{m})$ & $1.70 \pm 0.1$ & $1.66 \pm 0.05$ \\
Risk factors & & \\
Hypertension & - & $15(93.7)$ \\
Diabetes mellitus & - & $5(31.2)$ \\
Dyslipidemia $(\%)$ & $1(6.2)$ & $14(87.5)$ \\
Overweight $\left(\mathrm{BMl}>25\right.$ and $\left.<30 \mathrm{~kg} / \mathrm{m}^{2}\right)$ & $5(31.2)$ & $6(37.5)$ \\
Obesity (BMi $\left.>30 \mathrm{~kg} / \mathrm{m}^{2}\right)$ & $5(31.2)$ & $8(50)$ \\
Current smoking & - & $10(62.5)$ \\
Family history $(\mathrm{CAD})$ & $7(43.7)$ & $8(50)$ \\
Sedentary & $12(100)$ & $16(100)$ \\
\hline
\end{tabular}

Data are reported as the mean \pm SD or number (\%). BMI: body mass index, CAD: coronary artery disease. ${ }^{*} \mathrm{P}<0.005$ (nonparametric Mann-Whitney test). 
Table 2. Events and previous interventions, distribution of left ventricular ejection fraction, and medications being used in the coronary artery disease group.

\begin{tabular}{lc}
\hline $\begin{array}{l}\text { Events and previous } \\
\text { interventions }\end{array}$ & $\begin{array}{c}\text { Coronary artery } \\
\text { disease group }(\mathrm{n}=16)\end{array}$ \\
\hline AMI & $9(56.2)$ \\
PTCA & $9(56.2)$ \\
CABG & $3(18.7)$ \\
Ejection fraction of the left ventricle & \\
Normal EF $(>50 \%)$ & $12(75)$ \\
Reduced EF $(<50 \%)$ & $4(25)$ \\
Medications & \\
Beta-blockers & $16(100)$ \\
ACE inhibitors & $11(68.7)$ \\
Antagonists of angiotensin II receptor & $1(6.2)$ \\
Calcium channel blockers & $8(50)$ \\
Nitrate & $9(56.2)$ \\
Acetylsalicylic acid & $12(75)$ \\
Statins & $13(81.2)$ \\
Ticlopidine/clopidogrel & $3(18.7)$ \\
Oral anticoagulants & $2(12.5)$ \\
Diuretics & $7(43.7)$ \\
Oral hypoglycemic & $3(18.7)$ \\
Insulin & $1(6.2)$ \\
Fibrate & $1(6.2)$ \\
$\alpha-2$ adrenergic antagonist & $1(6.2)$ \\
\hline
\end{tabular}

Data are reported as number with percent within parentheses. AMI: acute myocardial infarction; PTCA: percutaneous transluminal coronary angioplasty; CABG: coronary artery bypass grafting; EF: ejection fraction; ACE: angiotensin-converting enzyme.

Analysis of agreement between the methods during the unloaded period in the HG showed a Lin's concordance coefficient of $0.42(95 \% \mathrm{Cl}=0.01-0.61)$ between the values that were predicted by the formula and the real values that were obtained in the CPET (Figure $3 A$ ). According to the Bland and Altman model, the mean difference $\left(\dot{\mathrm{V}} \mathrm{O}_{2 \text { unloaded (predicted) }}-\dot{\mathrm{V}} \mathrm{O}_{2 \text { unloaded (real) }}\right)$ was $39 \mathrm{~mL} / \mathrm{min}$ (95\% Cl=-127.08-204.92; Figure 3B). At peak effort, Lin's concordance coefficient was $0.08(95 \%$ $\mathrm{Cl}=-0.18-0.11$; Figure $3 \mathrm{C}$ ). According to the Bland and Altman model, the mean difference $\left(\dot{\mathrm{VO}}_{2 \text { peak (predicted) }}\right.$

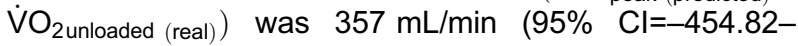
1168.07; Figure 3D).

In contrast, in the CG, during the unloaded condition, Lin's concordance coefficient between the values that were predicted by the formula and the real values that were obtained in the CPET was $0.33(95 \% \mathrm{Cl}=0.15-0.51$; Figure $4 \mathrm{~A})$. According to the Bland and Altman model, the mean difference $\left(\dot{\mathrm{V}}_{2}\right.$ unloaded (predicted) $\left.-\dot{\mathrm{V}} \mathrm{O}_{2 \text { unloaded (real) }}\right)$ was $116 \mathrm{~mL} / \mathrm{min}$ (95\% Cl=16.4-216.12; Figure 4B). At peak effort, Lin's concordance coefficient was 0.04 (95\% Cl=-0.03-0.13; Figure 4C). According to

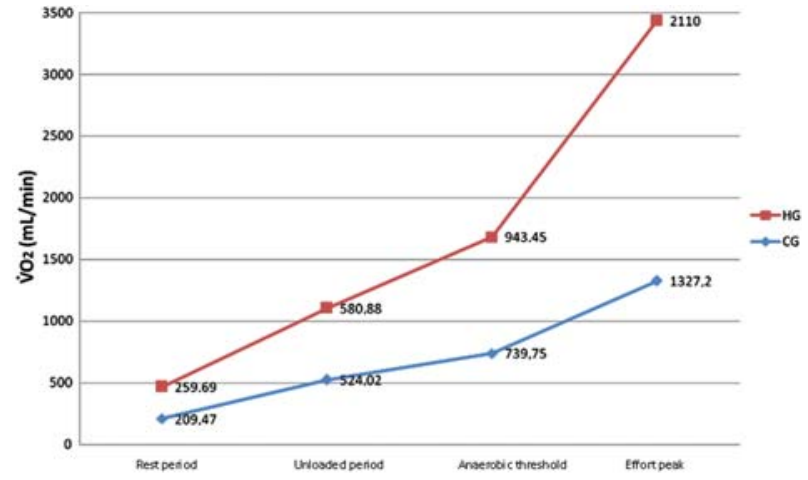

Figure 1. $\dot{\mathrm{VO}}_{2}$ under conditions of rest and effort. $\dot{\mathrm{V}}_{2}$ was directly obtained by a metabolic analysis system during the CPET in the healthy group $(\mathrm{HG})$ and coronary artery disease group (CG). $\mathrm{V}_{2}$ : oxygen uptake.

the Bland and Altman model, the mean difference $\left(\dot{\mathrm{V}} \mathrm{O}_{2 \text { unloaded (predicted) }}-\dot{\mathrm{V}} \mathrm{O}_{2 \text { unloaded (real) }}\right)$ was $890 \mathrm{~mL} / \mathrm{min}$ (95\% Cl=238.59-1541.95; Figure 4D).

\section{Discussion}

The Wasserman formula (9) has been routinely used in our institution for the choice of progressive load increment (power) applied to the cycle ergometer during the CPET for healthy individuals and those with CAD. Use of this method is based on an attempt to use a less empirical and subjective method of choosing the intensity of the power ramp to be applied during incremental effort tests on a cycle ergometer.

Tests of short duration with intense power increments generate an insufficient quantity of data, thus impairing their interpretation. In addition, a relatively large proportion of the energy that is generated in these tests is based on anaerobic sources. This fact compromises the response of the $\mathrm{O}_{2}$ transport variables and the quality and reliability of the exam because the individual may interrupt the test early because of muscle fatigue. Conversely, long tests with small power increments can prolong the period of effort. In these situations, measurements of $\mathrm{O}_{2}$ transport at submaximal effort are also compromised because of early termination of the exam. This termination is due to the discomfort caused by the mouthpiece of the system for metabolic analysis, by discomfort of the cycle ergometer's seat, lack of motivation, and even muscle fatigue $(7,9)$.

Some investigators have been searching for new methods to accurately estimate the cardiovascular functional reserve, using CPET individualized protocols capable of reaching the maximum aerobic power. Myers et al. (11) developed a questionnaire on daily life activities in elderly subjects that took into consideration chest pain, dyspnea, and fatigue (Veteran's Specific Activity Questionnaire). Using multivariable analysis, they observed that age and the responses to the questionnaire were able 
Table 3. Ventilatory variables that were obtained in the unloaded period and peak effort in the healthy and coronary artery disease groups.

\begin{tabular}{|c|c|c|}
\hline Unloaded period (real) & Coronary artery disease group $(n=16)$ & Healthy group $(n=12)$ \\
\hline$\dot{\mathrm{VO}}_{2 \text { unloaded (real) }}(\mathrm{mL} / \mathrm{min})$ & $524.02 \pm 66.76^{*}$ & $580.88 \pm 67.98$ \\
\hline RER & $0.91 \pm 0.08^{*}$ & $0.81 \pm 0.06$ \\
\hline$\dot{\mathrm{VO}}_{2 \text { unloaded (real) }}(\mathrm{mL} / \mathrm{min})$ & $1327.2 \pm 287.15^{\star}$ & $2110 \pm 335.83$ \\
\hline$\dot{\mathrm{V}} \mathrm{O}_{2 \text { unloaded (real) }}(\mathrm{mL} / \mathrm{kg} / \mathrm{min})$ & $16.38 \pm 3.46^{*}$ & $26.54 \pm 6.45$ \\
\hline HR (bpm) & $117 \pm 17^{*}$ & $164 \pm 12$ \\
\hline Work (watts) & $113.64 \pm 29.21^{*}$ & $177.28 \pm 22.63$ \\
\hline RER & $1.28 \pm 0.10^{*}$ & $1.16 \pm 0.08$ \\
\hline$\dot{\mathrm{V}}(\mathrm{L} / \mathrm{min})$ & $57.04 \pm 14.13^{*}$ & $75.39 \pm 13.06$ \\
\hline
\end{tabular}

Data are reported as mean $\pm \mathrm{SD}$. $\dot{\mathrm{V}} \mathrm{O}_{2}$ : oxygen uptake; RER: respiratory exchange ratio; HR: heart rate; bpm: beats per minute; $\dot{\mathrm{V}}$ : ventilation. ${ }^{*} \mathrm{P}<0.005$, compared to the healthy group (nonparametric MannWhitney test).

to predict exercise tolerance. They proposed a nomogram that predicted the peak metabolic equivalent and the ramp load increment on a treadmill. In 1996, another group studying patients with heart disease developed a new questionnaire based on daily life activities (12). Using multiple regression analysis, the authors observed that age, height, body mass, and the responses to the questionnaire were able to predict $\dot{\mathrm{V}} \mathrm{O}_{2 \text { peak }}$ for effort tests on a treadmill. However, most of the studies published in the literature did not detail the choice of the protocol that was used for individualization and performance of the effort tests, as concluded by Huggett et al. (10) in a review of maximum aerobic capacity in elderly people.

The first recommendation on the ideal duration of effort tests needed to reach maximum aerobic power was published in 1983 (3). This controversial study involved only five healthy male volunteers, who performed three incremental effort tests on a treadmill and three tests on a cycle ergometer. The authors concluded that, to obtain the highest $\dot{\mathrm{V}}_{2 \max }$ during an incremental effort test, a load increment needs to be selected that will permit a volunteer to reach the limit of his/her effort tolerance within $10 \pm 2 \mathrm{~min}$. Two other studies published in 1998 and 2003 demonstrated that reaching $\dot{\mathrm{V}} \mathrm{O}_{2 \max }$ is possible in incremental effort tests of prolonged duration (25-26 $\mathrm{min}$ ) in trained and untrained individuals $(13,14)$. However, slightly longer tests with a mean duration of $28 \mathrm{~min}$ resulted in a significantly lower $\dot{\mathrm{V}} \mathrm{O}_{2 \max }$ compared with tests with a mean duration of $11 \mathrm{~min}$ (15). Three subsequent studies (16-18) also
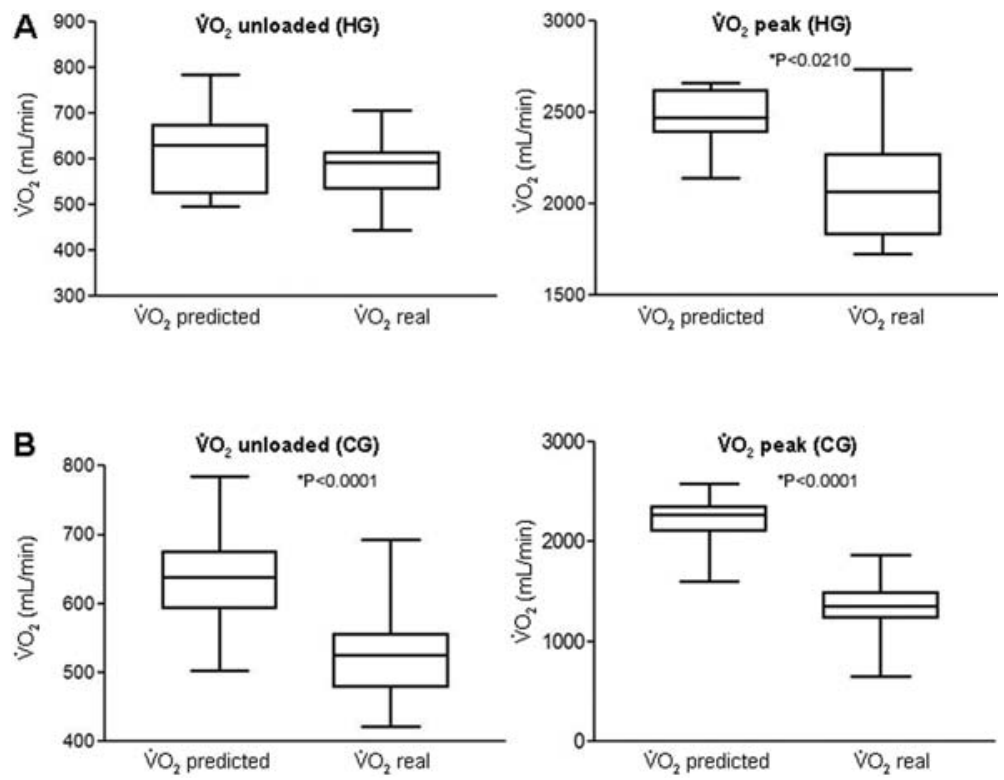

Figure 2. Box plots of $\dot{\mathrm{V}}_{2 \text { unloaded (predicted), }}$ $\dot{\mathrm{V}} \mathrm{O}_{2 \text { unloaded (real) }}, \dot{\mathrm{V}} \mathrm{O}_{2 \text { peak (predicted) }}$ and $\dot{\mathrm{VO}}_{2 \text { peak (real) }}$ in the healthy group $(\mathrm{HG})(A)$ and the coronary artery disease group $(C G)(B)$. The nonparametric Wilcoxon test was used for statistical analysis. $\dot{\mathrm{V}} \mathrm{O}_{2}$ : oxygen uptake. 

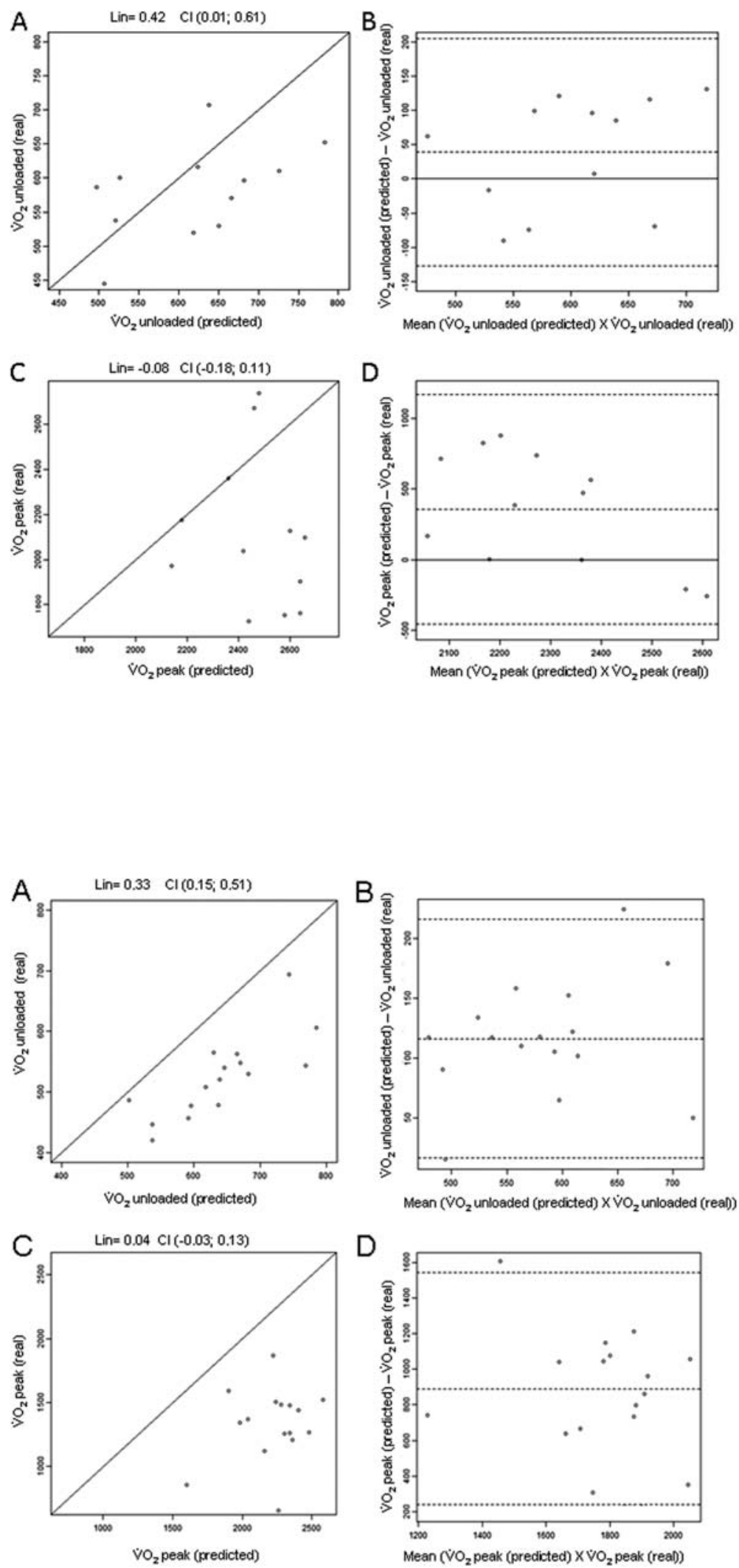

Figure 3. Lin's concordance coefficients and Bland and Altman analysis in the healthy group. Lin's concordance coefficient for $\mathrm{V}_{2}$ unloaded (predicted) $V S$ $\dot{\mathrm{V}} \mathrm{O}_{2 \text { unloaded (real) }}(A)$ and Bland and Altman analysis of $\dot{\mathrm{V}} \mathrm{O}_{2 \text { unloaded (predicted) }} v s \dot{\mathrm{V}} \mathrm{O}_{2 \text { unloaded (real) }}(B)$ in the unloaded condition. Lin's concordance coefficient for $\left(\dot{\mathrm{VO}}_{2 \text { peak (predicted) }} v s \dot{\mathrm{VO}}_{2 \text { unloaded (real) }}\right)(\mathrm{C})$ and Bland and Altman analysis of $\dot{\mathrm{VO}}_{2 \text { peak (predicted) and }}$ $\mathrm{VO}_{2 \text { unloaded (real) }}(D)$ at peak effort. $\mathrm{VO}_{2}$ : oxygen uptake. Dotted lines: mean $\pm 2 S D$.
Figure 4. Lin's concordance coefficients and Bland and Altman analysis in the coronary artery disease group. Lin's concordance coefficient for $\dot{\mathrm{V}} \mathrm{O}_{2 \text { unloaded (predicted) }} v s \dot{\mathrm{V}} \mathrm{O}_{2 \text { unloaded (real) }}(A)$ and

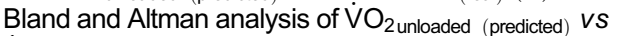
$\dot{\mathrm{V}} \mathrm{O}_{2 \text { unloaded (real) }}(B)$ in the unloaded condition. Lin's concordance coefficient for $\left(\dot{\mathrm{VO}}_{2 \text { peak (predicted) }} v s\right.$ $\dot{\mathrm{VO}}_{2 \text { unloaded (real) }}$ (C) and Bland and Altman analysis of $\dot{\mathrm{VO}}_{2 \text { peak (predicted) }}$ and $\dot{\mathrm{V}} \mathrm{O}_{2 \text { unloaded (real) }}(D)$ at peak effort. $\mathrm{VO}_{2}$ : oxygen uptake. Dotted lines: mean $\pm 2 S D$. 
reported significantly lower $\dot{\mathrm{V}}_{2 \max }$ values for tests with a mean time to exhaustion of 20-27 min compared with tests lasting 8-12 min.

However, another two studies showed that untrained men and women who were submitted to protocols with a mean time to exhaustion of 6.6-7.4 $\mathrm{min}$ were able to reach significantly higher $\dot{\mathrm{V}} \mathrm{O}_{2 \text { max }}$ values than those who were submitted to protocols with a duration of 8-12 min $(17,19)$. Kang et al. (20) also supported findings that recommend tests of short duration. The authors demonstrated that incremental effort tests lasting approximately 5 min enable $\mathrm{V}_{2 \max }$ values to be reached that are similar to those obtained with tests lasting 8-12 $\mathrm{min}$.

Incremental effort tests of short duration can be particularly appropriate for trained individuals because of a greater efficiency in the kinetics of oxygen transport (21). However, these short duration protocols may not be appropriate for patients with cardiorespiratory dysfunction. Agostoni et al. (22) reported significantly higher $\dot{\mathrm{V}}_{2 \max }$ values in protocols of incremental effort with a mean duration of $9.7 \pm 0.8 \mathrm{~min}$ compared with tests of $5.3 \pm 0.5$ min in patients with heart failure.

Risk factors for CAD have been documented in men older than 45 years, especially in those with known CAD $(23,24)$. Therefore, the age of subjects in the HG was an average of 10 years less than that of subjects in the CG because most of the risk factors (arterial hypertension, diabetes mellitus, and smoking) excluded HG volunteers. The remaining anthropometric characteristics, including body mass and height, were similar in the two groups.

\section{HG}

HG volunteers were selected to permit inclusion of subjects who were considered "healthy". However, they could be overweight and/or have dyslipidemia. This criterion was adopted because of the difficulty in finding sedentary men older than 40 years with no regular medications and without risk factors that were considered to be modifiable (25).

In our study, the difference detected between

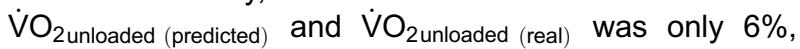
and did not reach significance. This result indicates that this component of the Wasserman formula may be appropriate for predicting $\dot{\mathrm{V}}_{2}$ during the unloaded period in this Brazilian sample of healthy volunteers. However, a significant difference was observed for peak effort, where $\dot{\mathrm{V}} \mathrm{O}_{2 \text { peak (real) }}$ was $14 \%$ lower than $\dot{\mathrm{V}} \mathrm{O}_{2 \text { peak (predicted). In this }}$ case, the formula overestimated the real capacity of an individual. Because of this difference, the ability of the formula to predict power increment (ramp) is impaired. Bland and Altman analysis also showed low agreement between the predicted and real $\mathrm{V}_{2}$. There are few data to compare with our results. Recently, another study (26) created and validated a formula that calculates $\dot{\mathrm{V}} \mathrm{O}_{2 \text { peak (predicted) }}$ in Brazilian healthy subjects. This previous study also showed that the Wassermann equation may not be suitable in our population.

\section{CG}

Despite the presence of impaired cardiac function, subjects in the CG were unable to achieve maximum effort when the load increment indicated by the Wasserman formula (9) was applied. Subjective adjustments were necessary according to the clinical conditions and degree of physical activity existing at the time of performing the CPET.

The differences detected in the analysis of the CG were of greater magnitude than those in the HG. In the

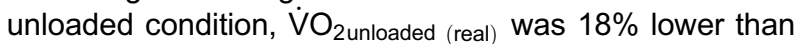
$\dot{\mathrm{V}} \mathrm{O}_{2 \text { unloaded (predicted), which was a significant difference. }}$ For peak effort, this difference was further increased and $\dot{\mathrm{V}} \mathrm{O}_{2 \text { unloaded (real) }}$ was $40 \%$ lower than $\dot{\mathrm{VO}}_{2 \text { peak (predicted). }}$. Therefore, in the CG, the measurements that were predicted by the Wasserman equation always overestimated the real aerobic capacity of the individuals. This fact indicates the need to continue to use a correction factor for power increment (ramp) in subjects with CAD who are evaluated by a routine CPET. Analysis of the agreement between $\mathrm{VO}_{2}$ measurements also showed an even more marked disagreement than that observed in the HG.

Wasserman et al. (9) made an important contribution to scientific knowledge and their work was the basis of our clinical application. However, our results suggest that there is variation related to the experimental design and the individual characteristics involved in the formula.

When we compared the behavior of cardiorespiratory variables during the CPET, we demonstrated a difference in functional capacity between patients with CAD and healthy individuals. The routine use of $\beta$-blockers is recommended in patients with CAD. The beneficial effects of this class of medications on improvement of symptomlimited effort capacity have been well established. These effects include a reduction in myocardial ischemia due to effort, an increase in the ischemic threshold, and an improvement in autonomic modulation $(27,28)$.

However, $\beta$-adrenoceptor blockade strongly influences metabolic and hemodynamic adaptations and ion balance during dynamic exercise. One of the main effects of the use of a $\beta$-blocker is a reduction of heart rate at rest and during dynamic exercise (27-31), as we observed in the present study. A lower heart rate was observed in subjects in the CG during the rest phase and during the various effort phases (unloaded, load increment, and peak effort) compared with subjects in the HG, who did not use medications.

Cardiac output and blood pressure are reduced by the use of $\beta$-blockers, although to a lesser extent than heart rate (29-32). According to Pearson et al. (30), this reduction may affect the normal vasoconstriction response in less active 
territories during exercise because cardiac output, and consequently muscle blood flow, are reduced. Therefore, although there is evidence that muscle fatigue is also caused by neuromuscular mechanisms $(33,34)$, this reduced blood flow may explain, at least in part, early fatigue.

Finally, lower $\mathrm{V}_{2}$ values were observed in the $\mathrm{CG}$ during rest and during the different phases of effort compared with the HG. This reduction, which has already been observed in other studies that evaluated the effect of administration of $\beta$-blockers on $\mathrm{O}_{2}$ transport $(30,31)$, may partially explain the reduction in $\mathrm{VO}_{2}$ in the $\mathrm{CG}$.

For a prediction or estimation equation, understanding the structural and local characteristics of the population for which the equation is created or validated is important. Predicting $\mathrm{V}_{2 \text { peak }}$ is challenging, mainly because factors, such as genetic differences, ethnicity, habits, body size, and physical activity levels of a particular population, may differ from the population in which the equation was initially tested.

\section{References}

1. Gibbons RJ, Balady GJ, Bricker JT, Chaitman BR, Fletcher GF, Froelicher VF, et al. ACC/AHA 2002 guideline update for exercise testing: summary article. A report of the American College of Cardiology/American Heart Association Task Force on Practice Guidelines (Committee to Update the 1997 Exercise Testing Guidelines). J Am Coll Cardiol 2002; 40: 1531-1540, doi: 10.1016/S0735-1097(02) 02164-2.

2. Guazzi $M$, Adams $V$, Conraads $V$, Halle $M$, Mezzani $A$, Vanhees L, et al. EACPR/AHA Scientific Statement. Clinical recommendations for cardiopulmonary exercise testing data assessment in specific patient populations. Circulation 2012; 126: 2261-2274, doi: 10.1161/CIR.0b013e $31826 \mathrm{fb} 946$.

3. Buchfuhrer MJ, Hansen JE, Robinson TE, Sue DY, Wasserman K, Whipp BJ. Optimizing the exercise protocol for cardiopulmonary assessment. J Appl Physiol Respir Environ Exerc Physiol 1983; 55: 1558-1564.

4. Huggett DL, Connelly DM, Overend TJ. Maximal aerobic capacity testing of older adults: a critical review. J Gerontol A Biol Sci Med Sci 2005; 60: 57-66, doi: 10.1093/gerona/60.1.57.

5. Albouaini K, Egred M, Alahmar A, Wright DJ. Cardiopulmonary exercise testing and its application. Postgrad Med J 2007; 83: 675-682, doi: 10.1136/hrt.2007.121558.

6. Milani RV, Lavie CJ, Mehra MR, Ventura HO. Understanding the basics of cardiopulmonary exercise testing. Mayo Clin Proc 2006; 81: 1603-1611, doi: 10.4065/81.12.1603.

7. Myers J, Bellin D. Ramp exercise protocols for clinical and cardiopulmonary exercise testing. Sports Med 2000; 30: 23-29, doi: 10.2165/00007256-200030010-00003.

8. Romer LM. Cardiopulmonary exercise testing in patients with ventilatory disorders. In: Winter EM, Jones AM, Davison $\mathrm{R}$, et al. (Editors), Sports and exercise physiology testing guidelines: exercise and clinical testing. London: Routledge; 2007. p 179-188.

\section{Study limitations}

As in other seminal studies $(3,9)$, our study has several limitations. Our sample size was small in both groups, but our strict selection criteria enabled the groups to be uniform.

The present study provides initial evidence that the Wasserman formula does not appear to be appropriate for prediction of functional capacity of Brazilian volunteers, regardless of whether they are apparently healthy or have CAD. Therefore, we cannot precisely predict the power increment (ramp) in incremental CPET on a cycle ergometer. When healthy subjects are compared with those with $\mathrm{CAD}$, the disagreement between measurements is much more marked in the latter than the former.

\section{Acknowledgments}

This study was supported by CAPES and FAEPAHCFMRP-USP.

9. Wasserman K, Hansen JE, Sue D, Whipp BJ, Casaburi R. Principles of exercise testing and interpretation. 4th edn. Philadelphia: Lippincott Williams and Wilkins; 2004.

10. Huggett DL, Connelly DM, Overend TJ. Maximal aerobic capacity testing of older adults: a critical review. J Gerontol A Biol Sci Med Sci 2005; 60: 57-66, doi: 10.1093/gerona/60.1.57.

11. Myers J, Do D, Herbert W, Ribisl P, Froelicher VF. A nomogram to predict exercise capacity from a specific activity questionnaire and clinical data. Am J Cardiol 1994; 73: 591-596, doi: 10.1016/0002-9149(94)90340-9.

12. Rankin SL, Briffa TG, Morton AR, Hung J. A specific activity questionnaire to measure the functional capacity of cardiac patients. Am J Cardiol 1996; 77: 1220-1223, doi: 10.1016/ S0002-9149(97)89157-6.

13. Bentley DJ, McNaughton LR. Comparison of $W($ peak), $\mathrm{VO}_{2}$ (peak) and the ventilation threshold from two different incremental exercise tests: relationship to endurance performance. J Sci Med Sport 2003; 6: 422-435, doi: 10.1016/ S1440-2440(03)80268-2.

14. Bishop D, Jenkins DG, Mackinnon LT. The effect of stage duration on the calculation of peak $\mathrm{VO}_{2}$ during cycle ergometry. J Sci Med Sport 1998; 1: 171-178, doi: 10.1016/ S1440-2440(98)80012-1.

15. Weston SB, Gray AB, Schneider DA, Gass GC. Effect of ramp slope on ventilation thresholds and $\mathrm{VO}_{2}$ peak in male cyclists. Int J Sports Med 2002; 23: 22-27.

16. Froelicher VF Jr, Brammell H, Davis G, Noguera I, Stewart A, Lancaster MC. A comparison of three maximal treadmill exercise protocols. J Appl Physiol 1974; 36: 720-725.

17. Pollock ML, Bohannon RL, Cooper KH, Ayres JJ, Ward A, White SR, et al. A comparative analysis of four protocols for maximal treadmill stress testing. Am Heart $J$ 1976; 92: 39-46, doi: 10.1016/S0002-8703(76)80401-2.

18. Pollock ML, Foster C, Schmidt D, Hellman C, Linnerud AC, Ward A. Comparative analysis of physiologic responses to 
three different maximal graded exercise test protocols in healthy women. Am Heart J 1982; 103: 363-373, doi: 10.1016/0002-8703(82)90275-7.

19. Myers J, Buchanan N, Walsh D, Kraemer M, McAuley P, Hamilton-Wessler $\mathrm{M}$, et al. Comparison of the ramp versus standard exercise protocols. J Am Coll Cardiol 1991; 17: 1334-1342, doi: 10.1016/S0735-1097(10)80144-5.

20. Kang J, Chaloupka EC, Mastrangelo MA, Biren GB, Robertson RJ. Physiological comparisons among three maximal treadmill exercise protocols in trained and untrained individuals. Eur J Appl Physiol 2001; 84: 291-295.

21. Caputo F, Mello MT, Denadai BS. Oxygen uptake kinetics and time to exhaustion in cycling and running: a comparison between trained and untrained subjects. Arch Physiol Biochem 2003; 111: 461-466, doi: 10.3109/13813450312331342337.

22. Agostoni P, Bianchi M, Moraschi A, Palermo P, Cattadori G, La Goia R, et al. Work-rate affects cardiopulmonary exercise test results in heart failure. Eur $J$ Heart Fail 2005; 7: 498-504.

23. Klecha A, Kawecka-Jaszcz K, Bacior B, Kubinyi A, Pasowicz $M$, Klimeczek $P$, et al. Physical training in patients with chronic heart failure of ischemic origin: effect on exercise capacity and left ventricular remodeling. Eur J Cardiovasc Prev Rehabil 2007; 14: 85-91, doi: 10.1097/HJR.0b013e32 $80114 \mathrm{f} 12$.

24. Milani M, Kozuki RT, Crescêncio JC, Papa V, Santos MDB, Bertini $C Q$, et al. Efeito do treinamento físico aeróbico em coronariopatas submetidos a um programa de reabilitação cardiovascular. Medicina 2007; 40: 403-411.

25. Yusuf S, Hawken S, Ounpuu S, Dans T, Avezum A, Lanas F, et al. Effect of potentially modifiable risk factors associated with myocardial infarction in 52 countries (the INTERHEART study): case-control study. Lancet 2004; 364: 937-952, doi: 10.1016/S0140-6736(04)17018-9.
26. Almeida AEM, Stefani CM, Nascimento AG, Almeida NM, Santos AC, Ribeiro JP, et al. A equation for the prediction of oxygen consumption in a Brazilian population. Arq Bras Cardiol 2014; 103: 299-307.

27. Gibbons RJ, Abrams J, Chatterjee K, Daley J, Deedwania PC, Douglas JS, et al. ACC/AHA 2002 guideline update for the management of patients with chronic stable angina - summary article: a report of the American College of Cardiology/American Heart Association Task Force on Practice Guidelines (Committee on the Management of Patients With Chronic Stable Angina). Circulation 2003; 107: 149-158, doi: 10.1161/01.CIR.0000047041. 66447.29.

28. César LAM, et al. Diretriz de angina estável. Arq Bras Cardiol 2004; 83 (Supl 2): 6-43.

29. Hawkins MN, Barnes Q, Purkayastha S, Eubank W, Ogoh S, Raven PB. The effects of aerobic fitness and beta1-adrenergic receptor blockade on cardiac work during dynamic exercise. J Appl Physiol 2009; 106: 486-493.

30. Pearson SB, Banks DC, Patrick JM. The effect of betaadrenoceptor blockade on factors affecting exercise tolerance in normal man. Br J Clin Pharmacol 1979; 8: 143-148.

31. Tesch PA, Kaiser P. Effects of beta-adrenergic blockade on $\mathrm{O}_{2}$ uptake during submaximal and maximal exercise. J Appl Physiol Respir Environ Exerc Physiol 1983; 54: 901-905.

32. Mier CM, Domenick MA, Wilmore JH. Changes in stroke volume with beta-blockade before and after 10 days of exercise training in men and women. J Appl Physiol 1997; 83: 1660-1665.

33. Asmussen E. Muscle fatigue. June 1979. Med Sci Sports Exerc 1993; 25: 411-420.

34. Hunter SK, Duchateau J, Enoka RM. Muscle fatigue and the mechanisms of task failure. Exerc Sport Sci Rev 2004; 32: 44-49, doi: 10.1097/00003677-200404000-00002. 